\title{
The Walking Trail-Making Test is an early detection tool for mild cognitive impairment
}

\author{
This article was published in the following Dove Press journal: \\ Clinical Interventions in Aging \\ 7 January 2014 \\ Number of times this article has been viewed
}

\section{Anaick Perrochon Gilles Kemoun}

Laboratoire Mobilité, Vieillissement, Exercice (MOVE), EA 63।4, Faculté des Sciences du Sport, Université de Poitiers, 8 Allée Jean Monnet, 86000 Poitiers, France; ISIS, Research Institute on Handicap and Aging, Paris, France
Correspondence: Anaick Perrochon Laboratoire Mobilité, Vieillissement, Exercice (MOVE), EA 63।4, Faculté des Sciences du Sport, Université de Poitiers, 8 Allée Jean Monnet, 86000 Poitiers, France

Tel +33 679723648

Email anaick.perrochon@hotmail.fr
Background: Executive function impairment (in particular, mental flexibility) in the elderly, and in patients with mild cognitive impairment (MCI), is strongly correlated with difficulties in performing complex walking tasks. The aim of this study was to determine if the adaptation of a neuropsychological test (the Trail-Making Test), to evaluate executive functions during walking, can be an early detection tool for cognitive impairment.

Methods: Fifty subjects (15 young, 20 older, presumably healthy, and $15 \mathrm{MCI}$ ) were first evaluated for cognitive functions (Mini-Mental State Examination, Frontal Assessment Battery, and Trail-Making Test) and motor functions (10-meter walking test). All subjects then performed a spatial navigation, or a complex walking test (the Walking Trail-Making Test: [WTMT]), and their spatiotemporal walking variables were analyzed using cluster analysis.

Results: Following evaluation of WTMT locomotor performance, cluster analysis revealed three groups that were distinctly different in age and cognitive abilities: a group of young subjects, a group of healthy older subjects, MCI subjects with amnestic impairment, and a group of MCI subjects with executive function impairment. The WTMT enabled early detection, (ie, borderline MCI) of dysexecutive impairment, with $78 \%$ sensitivity and $90 \%$ specificity.

Conclusion: The WTMT is of interest in that it can help provide early detection of dysexecutive cognitive impairment.

Keywords: spatial navigation, walking, trail making test, detection, mild cognitive impairment

\section{Introduction}

The concept of mild cognitive impairment (MCI) is classified, in older subjects, as a more deficient state than expected for their age and sociocultural level, but not severe enough to define it as dementia. This state is often characterized as the prodromal phase of several dementia pathologies, ${ }^{1}$ and so, its early diagnosis is of major importance in the implementation of adapted care.

Executive functions (EF) are among cognitive functions that are rapidly altered in MCI subjects. ${ }^{2,3}$ Several studies have reported that an early EF deficit in subjects with MCI can predict the occurrence of dementia pathologies. ${ }^{4,5} \mathrm{EF}$ includes a group of cognitive processes (mental inhibition, planning, mental flexibility, updating, control abilities) that enable a subject to adapt to a new and/or complex situation. ${ }^{6}$ Mental flexibility, a dominant cognitive function in most cognitive models, ${ }^{7}$ is defined as the ability to go from one cognitive task to another. Among the neuropsychological tests that evaluate this cognitive function, the Trail-Making Test (TMT) ${ }^{8}$ is the most-used clinically, because it can be administered quickly and it evaluates several aspects: visual conception, visuospatial abilities, visuomotor coordination, 
divided attention, and alternation tasks. ${ }^{9}$ TMT also has good power to predict the development of dementia, ${ }^{4}$ which justifies its use for the detection of cognitive impairment in older subjects.

Many other neuropsychological tests that evaluate EF are used in the diagnosis of MCI. ${ }^{10,11}$ However, most of these tests have numerous limitations (the problem of novelty, lack of sensitivity and specificity, patient cognitive reserve, etc). ${ }^{12,13}$ This recent observation underscores the need to find new detection indicators for cognitive impairment.

With this in perspective, a new approach associates walking performance of older subjects with the presence and/or appearance of cognitive impairment. In fact, numerous longitudinal studies have reported that a reduction in walking speed is associated with the occurrence of negative events, such as cognitive decline ${ }^{14}$ and dementia - of the Alzheimer type ${ }^{15}$ or non-Alzheimer type. ${ }^{16,17}$ Gait and cognition, long studied separately, appear to be closely linked, beginning in the early stages of dementia. ${ }^{18}$ Indeed, the association of motor and cognitive impairment in subjects with MCI is strongly associated with a high risk of developing subsequent dementia. ${ }^{19,20}$

This new approach supposes the existence of a direct link between EF performances (mental inhibition, working memory, etc) and single- and dual-task walking abilities. This relationship has been shown in healthy older subjects ${ }^{21,22}$ and in subjects with dementia. ${ }^{23}$ Moreover, several studies have revealed that TMT score is strongly correlated with overall physical abilities, ${ }^{24}$ as measured in functional tests ${ }^{24,25}$ and walking performance in complex situations. ${ }^{26-29}$

At the same time, studies in the literature have reported several adaptations of TMT to locomotion, creating original and complex walking tasks. ${ }^{30-32}$ In 2008, Persad et al showed, through one of these tests, called the Walking Trail-Making Test (WTMT), that subjects with dementia and MCI with dysexecutive syndrome differentiated themselves from other older subjects by locomotor performance that was significantly more altered. ${ }^{31}$ In this context, new walking tests that included spatial navigation were developed for early detection of cognitive impairment in an ageing population. ${ }^{33} \mathrm{We}$ demonstrated that an adaptation of the Stroop Test to walking, by analysis of dual-task locomotor performances, made early detection of dysexecutive-type cognitive impairment possible in patients who no longer had diagnoses of MCI, but were considered as blMCI. ${ }^{33}$

The aim of this study was to determine if the analysis of walking variables during an adaptation of TMT to locomotion (WTMT) is an effective means to detect cognitive impairment.

\section{Materials and methods}

\section{Subjects}

Our study population was made up of 15 young subjects (mean age: $21.1 \pm 2.2$ years [20-30 years]) and 35 older adults (mean age: $75.3 \pm 6.8$ years [ $65-85$ years]). This population included young adults, healthy older subjects, and subjects with MCI from high socioprofessional categories; all subjects had college graduate education levels. The healthy older subjects were recruited from cultural associations; the young subjects were students. MCI patients were evaluated by a geriatrician or a neurologist (in memory centers) and fulfilled the criteria established by Petersen (2004). ${ }^{1}$ These subjects presented a memory complaint or had cognitive impairment, identified by neuropsychological tests. They also had an absence of functional impairment and, of course, an absence of dementia. ${ }^{1}$ The cognitive work-up used to determine cognitive performance enabled us to identify a group of 26 healthy subjects: 15 young healthy $(\mathrm{YH})$ subjects, 11 older healthy $(\mathrm{OH})$ subjects, and 15 MCI subjects, divided into subgroups according to Petersen's criteria (six subjects with isolated impairment of MCI amnestic functions [aMCI]; three subjects with non-amnestic MCI, with isolated impairment of executive functions [naMCI]; and six subjects with multiple domain MCI cognitive impairment with dysexecutive symptoms [mdMCI]). We noted and differentiated nine subjects who were not diagnosed with MCI, but whose EF test performances were consistently at the threshold of pathologic levels. These subjects formed another group, which we described in a previous study as "borderline MCI" (blMCI). ${ }^{33}$

Inclusion criteria were: to be willing to actively participate in the study, live in a non-institutional environment, and be able to get around on an everyday basis without technical assistance. Exclusion criteria were: uncorrected visual impairment, a neurologic pathology (Parkinson's disease, stroke, etc), orthopedic surgery of the lower limbs, depression, and the taking of medications that could influence posture and/or gait. All subjects consulted with a doctor, to verify inclusion and exclusion criteria. Prior to inclusion in the study, each subject signed informed consent forms, in order to participate.

\section{Evaluation of cognitive and motor abilities}

The subjects first underwent an evaluation of cognitive functions by a neuropsychologist, using the Mini-Mental State Examination $^{34}$ and the Frontal Assessment Battery. ${ }^{35}$ Each subject was assessed using the Stroop Color-Word test, the Wechsler Adult Intelligence Scale (WAIS) III, the ClockDrawing Test, and the Corsi Block-Tapping Test. 
The dominant cognitive function in our study was mental flexibility, which was tested using the TMT. ${ }^{8}$ The TMT is a paper and pencil test that consists of linking targets as quickly as possible, in numeric order in Part A, (ie, 1-25), and alternating between numbers and letters in Part B (ie, 1-A-2-B3-C). ${ }^{8}$ It evaluates visual perception abilities, perceptual/ motor speed, and speed processing in Part A, and mental flexibility in Part B. Delta TMT ( $\triangle$ TMT) (TMT B-TMT A) is considered the best indicator of EF performance. ${ }^{9}$

Finally, we performed a motor evaluation of single-task, spontaneous walking for 10 minutes, in a normal environment on a pressure-sensitive, portable walkway (Length: $793 \mathrm{~cm}$; Width: $61 \mathrm{~cm}$; Height: $0.6 \mathrm{~cm}$ ) (GAITRite $^{\circledR}$, CIR Systems Inc, Sparta, NJ, USA). In order to derive a value representative of single-task locomotor abilities, subjects were asked to walk five times, at a spontaneous pace, from which walking speed, frequency, cycle time, and time in double support were calculated.

\section{Complex walking task: the Walking Trail-Making Test}

The WTMT is an adaptation to walking of a traditional neuropsychological test, the TMT. We used an experimental protocol similar to that of Persad, ${ }^{31}$ by reproducing the different stages proposed by those authors (Figure 1). In the WTMT-N part, the walking circuit is always performed in the same order. First, the subject is asked to walk on 20 numeric targets, in increasing order (ie, 1-20). In the WTMT-A part, the WTMT-N includes 20 other, associated targets, considered as distraction targets. These targets, which the subject must avoid during the test, have been added to provide an attentional aspect to the walking test. Finally, the third part, called WTMT-B, evaluates mental flexibility abilities. For this test, subjects are asked to walk on targets, alternating between numbers and letters, while avoiding the 20 distraction targets (ie, 1-A-2-B-3-C). Each target is eight centimeters in diameter.

The main modification of the TMT, relative to the 2008 study by Persad et al, is that our targets were drawn on a removable cloth support of five-meter length, which covered the eight-meter electronic walkway. This device, therefore, provided a recording of all of the WTMT walking variables. In order to study locomotor performances, we selected four spatiotemporal walking variables: speed, frequency, double support time, and cycle time.

In this circumstance, the carpet is black and the targets are white, in order to increase contrast and reduce the risk of instability that is linked to the treatment of information. Indeed, in 1991, Lord et al demonstrated that reduction of ability to distinguish characters with low contrast was a strong predictor of the risk of falling. ${ }^{36}$
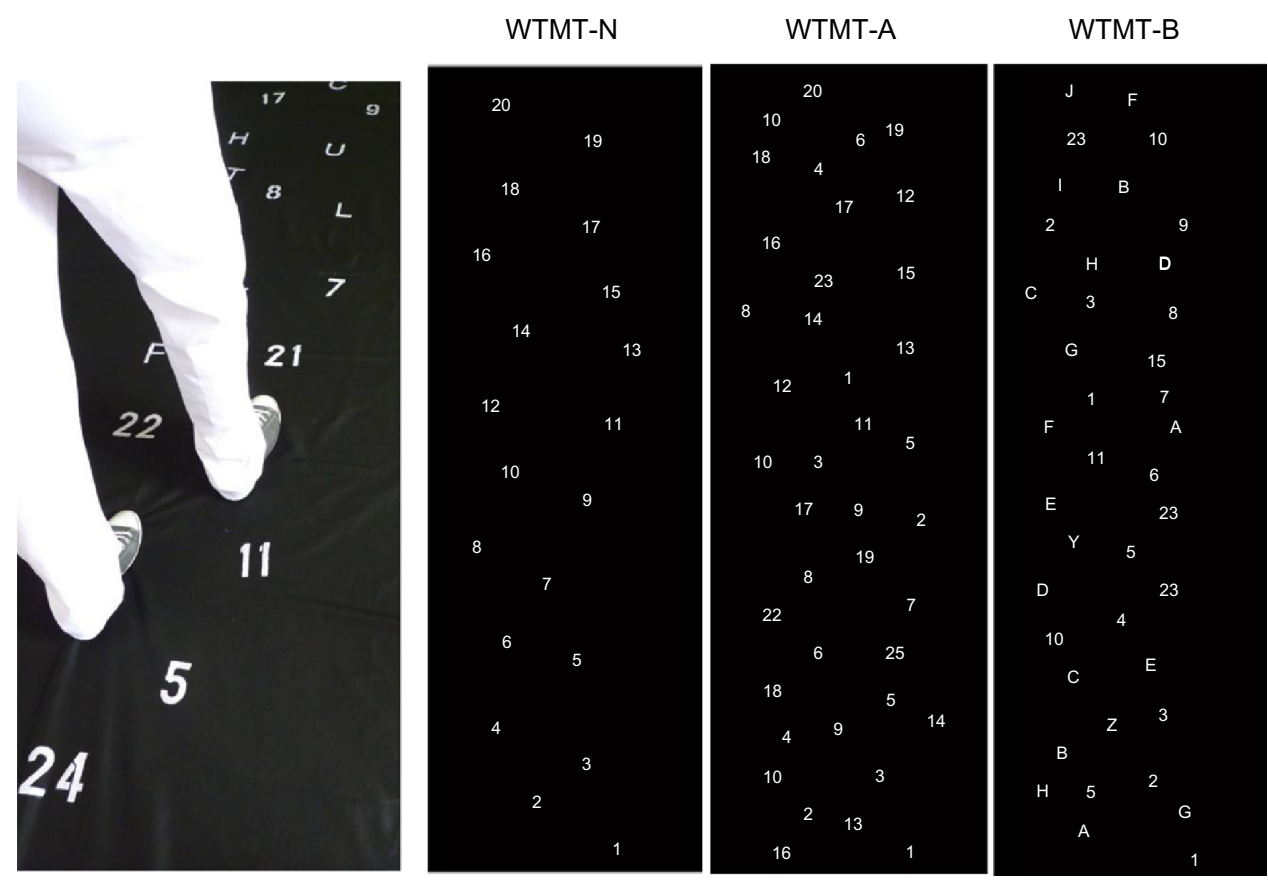

Figure I Illustration of WTMT experimental conditions.

Notes: There are three different walking conditions: WTMT-N, where the subject must walk in ascending order on numbered targets I-20; WTMT-A, where the subject must walk in ascending order on targets I-20, avoiding distractors; and WTMT-B, where the subject must walk alternating between numbers and letters in ascending order, while avoiding distractors.

Abbreviation: WTMT, Walking Trail-Making Test. 
The subjects received the following instruction, to perform the two tasks as best they could: "Walk as fast as possible and do the WTMT exercise without making any mistakes." However, no priority was given to one domain or the other. Each condition had a familiarization and learning phase (over a distance of 2 meters), which was repeated until the subject understood the task to be accomplished (a maximum of three repetitions were allowed). During the test, the result was considered to be positive when the subject touched the correct targets with his or her foot. Each condition was filmed using a webcam $(640 \times 480$ pixel resolution $)$ that was synchronized with the electronic walkway, in order to detect errors accurately. Indeed, we used video recording only for error analysis. This video camera was placed in front of the electronic walkway, in line with the anteroposterior axis of travel. We noted the number of errors the subjects made on the test (expressed in percentages of subjects who made the fewest errors).

\section{Statistics}

Our aim was to detect the possible existence of executive function impairment from WTMT walking characteristics only. The ascendant hierarchic classification method, or cluster analysis (Ward's method, ${ }^{37}$ Euclidean distance), makes it possible to regroup subjects, according to their functional similarities, from the spatiotemporal parameters of walking.

The differences between groups formed by the cluster analysis method, be it WTMT or cognitive and functional tests, were studied using analysis of variance (ANOVA), followed by a post hoc Tukey's test. The correlation coefficient between $\triangle \mathrm{TMT}$ and single-task walking speed and the correlation coefficient between $\triangle$ TMT and WTMT were studied using Pearson's $R$ coefficient. Statistical analysis was performed using Statistica Version 9 software (StatSoft Inc, Tulsa, OK, USA). Results were considered significant at $P<0.05$.

Finally, when one attempts to detect a syndrome from a test, one determines the sensitivity and specificity values for this test. For our experimental conditions, sensitivity and specificity values for the detection of the MCI syndrome by WTMT were calculated using the following formulas:

$$
\begin{aligned}
\text { Sensitivity }= & \text { Number of subjects with MCI with low } \\
& \begin{aligned}
& \text { performance on the WTMT } \div \text { total number } \\
& \text { of subjects with MCI. }
\end{aligned} \\
\text { Specificity }= & \begin{array}{l}
\text { Number of healthy subjects with high } \\
\text { performance on the WTMT } \div \text { total number } \\
\text { of healthy subjects. }
\end{array}
\end{aligned}
$$

Low performance refers to the motor performance of the group with the largest deficit in the WTMT, and high performance refers to the group with the best gait parameters in navigational tasks. ${ }^{33}$

\section{Results \\ WTMT cluster analysis}

WTMT cluster analysis (Figure 2) includes the subjects' locomotor performances for the entire test. Classification by the ascendant hierarchic method revealed three distinct branches, with a Euclidean distance of $<20$ and a reunification at 50 (Figure 2). The $R$ ratio calculation ${ }^{38}$ distinguished three, apparently different, walking abilities for the entire test.

\section{$\mathrm{MCl}$ detection}

We studied the morphological and psychobehavioral characteristics (age, cognitive ability) of the subjects in each group (Figure 3). Overall, the subjects in Group 2 were much younger than those in Groups 1 and 3, and the subjects in Group 1 had significantly more EF deterioration (Frontal Assessment Battery; $\Delta \mathrm{TMT}$ ) than the subjects in Groups 2 and 3 (Table 1). More precisely, Group 1 mainly included older subjects presenting a decline in $\mathrm{EF}$ (naMCI, $\mathrm{mdMCI}$ ), or cognitive fragility of the dysexecutive type (blMCI), including 17 older subjects (five older, 12 very elderly): two healthy, six mdMCI, five blMCI, three naMCI, and one aMCI, whereas Group 2 was made up of 15 subjects (14 young, one older): 14 young and healthy, and one aMCI. Finally, Group 3 was more heterogeneous. It was made up of 18 subjects (one young, 12 older, five very elderly): ten healthy, four blMCI, and four aMCI.

The WTMT detected dysexecutive syndrome (naMCI and mdMCI) with $100 \%$ sensitivity and $80 \%$ specificity. This test also made it possible to detect EF fragility, beginning at the blMCI stage, with $78 \%$ sensitivity and $90 \%$ specificity.

\section{Gait characteristics}

We studied the functional abilities of these three cluster analysis groups. We first observed that the subjects in Group 1 walked more slowly than the subjects in Group 2 during the single-task walking test, and that there was not a significant difference between the subjects in Groups 2 and 3 (Table 1). On the other hand, during the WTMT, the locomotor performances of Group 1 subjects were significantly worse than those of Group 3, whose performances were worse than those of Group 2 (Table 1). This impairment in locomotor abilities during WTMT was observed by reductions in walking speed $(\mathrm{F}=78.7 ; P<0.001)$ and walking 


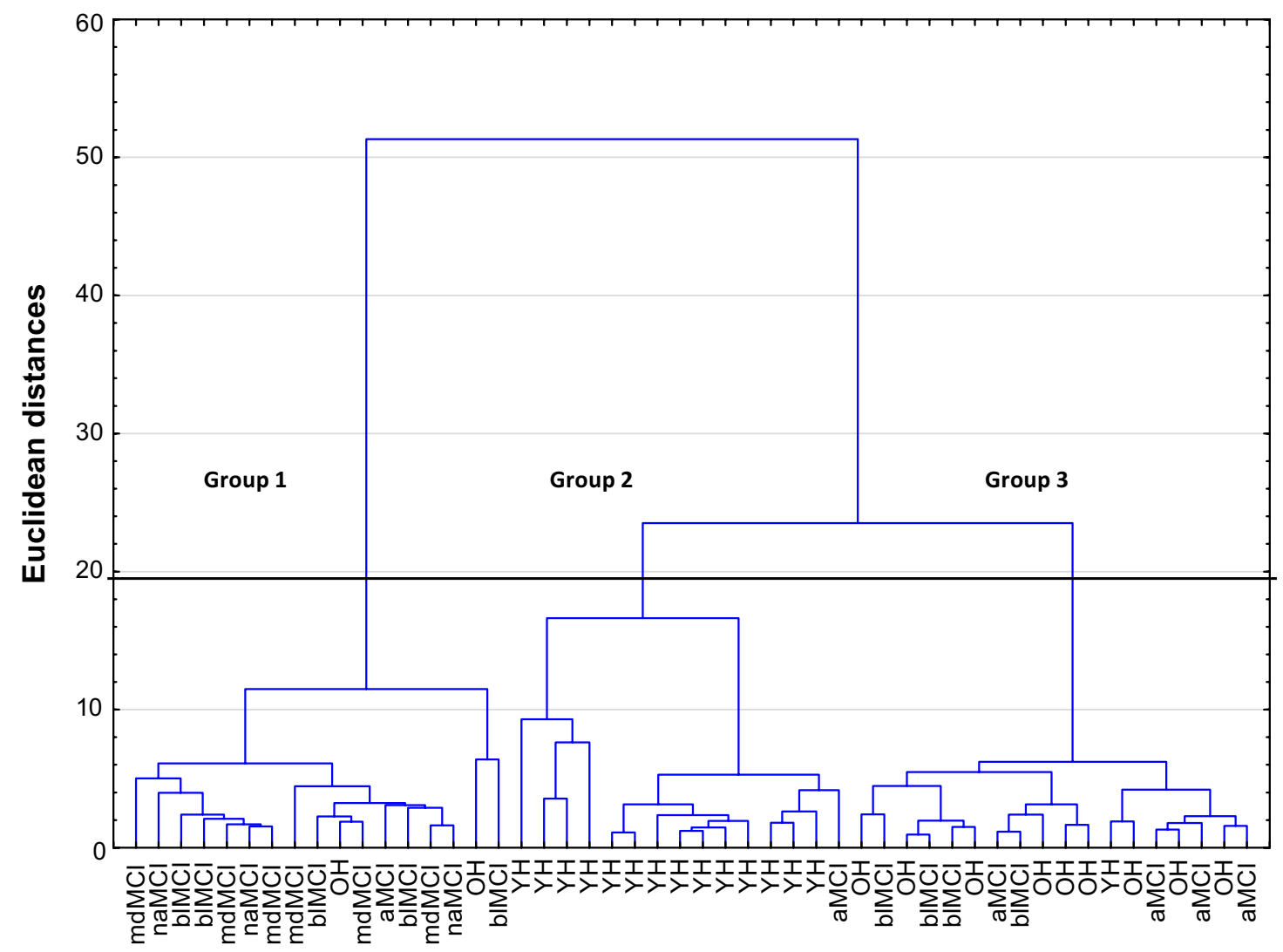

Figure 2 Dendrogram of spatio-temporal walking variables during WTMT.

Note: The subjects are grouped in pairs by similarity of the selected variables.

Abbreviations: $\mathrm{YH}$, young healthy; $\mathrm{OH}$, older healthy; blMCl, borderline $\mathrm{MCl}$; naMCl, non-amnestic $\mathrm{MCl}$ - executive impairment only; a $\mathrm{MCl}$, amnestic $\mathrm{MCl}$; mdMCl, multiple domain amnestic MCl; WTMT, Walking Trail-Making Test.
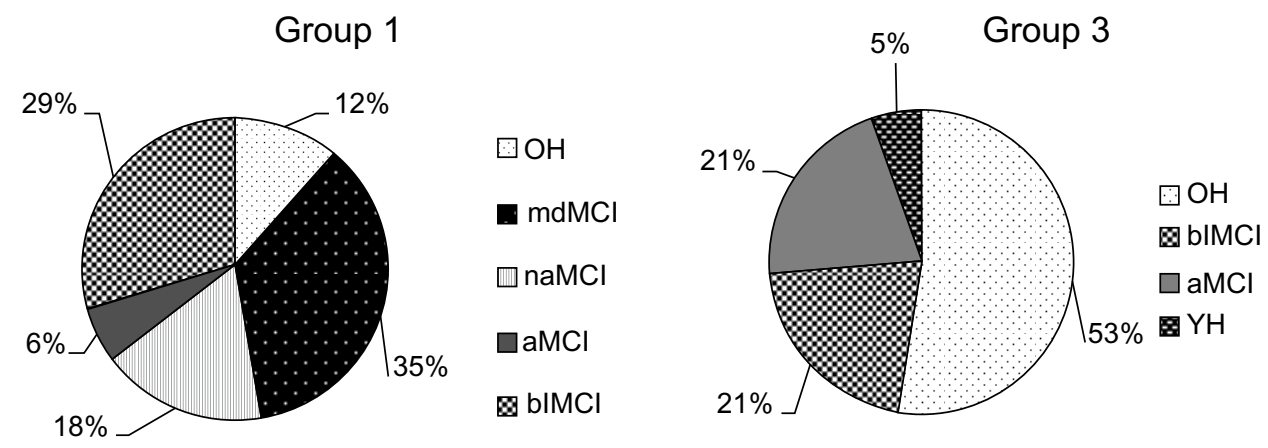

\section{Group 2}

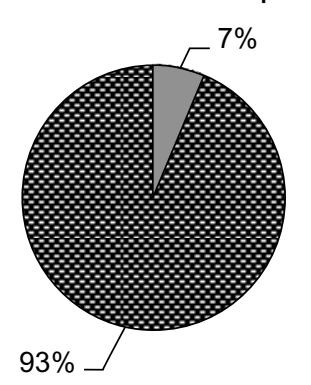

$\square \mathrm{aMCl}$

图 $\mathrm{YH}$

Figure 3 Breakdown by circular diagram of the cognitive profiles of the subjects in each group from the cluster analysis.

Abbreviations: $\mathrm{YH}$, young healthy; $\mathrm{OH}$, older healthy; blMCl, borderline $\mathrm{MCl}$; naMCl, non-amnestic $\mathrm{MCl}$ - executive impairment only; a $\mathrm{MCl}$, amnestic $\mathrm{MCl}$; mdMCl, multiple domain amnestic $\mathrm{MCl}$. 
Table I Demographic, clinical, and locomotor characteristics of the different groups formed by cluster analysis

\begin{tabular}{|c|c|c|c|}
\hline \multirow[t]{2}{*}{ Variable } & \multicolumn{3}{|c|}{ Group from the clusters } \\
\hline & $\begin{array}{l}\text { Group I } \\
(n=17)\end{array}$ & $\begin{array}{l}\text { Group } 2 \\
(n=15)\end{array}$ & $\begin{array}{l}\text { Group } 3 \\
(n=18)\end{array}$ \\
\hline Age (years) & $77.6 \pm 7.0$ & $28.0 \pm 11.6 *, \#$ & $70.1 \pm 12.5^{*}$ \\
\hline Women (\%) & I5 (88.3) & $12(80)$ & $12(66.6)$ \\
\hline \multicolumn{4}{|l|}{ Cognitive tests } \\
\hline MMSE & $27.9 \pm 1.4$ & $28.3 \pm 1.0$ & $28.6 \pm 1.0$ \\
\hline$F A B$ & $15.6 \pm 1.7$ & $17.6 \pm 0.6 *$ & $16.9 \pm 0.8^{*}$ \\
\hline$\Delta \mathrm{TMT}$ (seconds) & $56.2 \pm 37.2$ & $16.9 \pm 8.2^{* \# \#}$ & $36.9 \pm 12.8^{*}$ \\
\hline $\begin{array}{l}\text { At least I error in the } \\
\text { WTMT (proportion of the } \\
\text { population, \%) }\end{array}$ & 52.9 & $0.00 *$ & $22.2^{*}$ \\
\hline \multicolumn{4}{|l|}{ Single-task walking } \\
\hline $\begin{array}{l}\text { Walking speed for } 8 \text { minutes } \\
\text { (centimeters per second) }\end{array}$ & $108.3 \pm 17.6$ & $127.0 \pm 16.8 *$ & $116.9 \pm 15.1$ \\
\hline \multicolumn{4}{|l|}{ WTMT walking } \\
\hline $\begin{array}{l}\text { Walking speed } \\
\text { (centimeters per second) }\end{array}$ & $27.1 \pm 11.1$ & $53.1 \pm 20 . I^{*, \#}$ & $38.8 \pm 10.6 *$ \\
\hline Frequency (steps per minute) & $69.0 \pm 27.7$ & $132.9 \pm 49.2^{\text {*,\# }}$ & $96.7 \pm 25.6 *$ \\
\hline Walking cycle time (seconds) & $2.2 \pm 1.2$ & $1.0 \pm 0.3^{*, \#}$ & $1.3 \pm 0.4 *$ \\
\hline Double support time & $46.6 \pm 12.5$ & $31.9 \pm 9.0 * \#$ & $37.8 \pm 7.1^{*}$ \\
\hline $\begin{array}{l}\text { At least I error in the } \\
\text { WTMT (proportion of the } \\
\text { cohort, \%) }\end{array}$ & 52.9 & $0.06 * \#$ & 44.4 \\
\hline
\end{tabular}

Notes: Values are mean \pm standard deviation. $* P<0.00$ I, compared against Group I. ${ }^{\# P}<0.00$ I, compared against Group 3 .

Abbreviations: WTMT, Walking Trail-Making Test; MMSE, Mini-Mental State Examination; FAB, Frontal Assessment Battery; $\triangle T M T$, (Part B-Part A).

frequency ( $\mathrm{F}=76.4 ; P<0.001)$, and by increases in cycle time $(\mathrm{F}=113.3 ; P<0.001)$ and percentage in double support (F=47.6; $P<0.001$ ) (Table 1). Lastly, the number of subjects making errors was higher in Group 1 than in the other groups $(P=0.009)$ (Table 1).

Finally, as for the link between cognitive and motor abilities, performance in $\triangle \mathrm{TMT}$ was significantly correlated with WTMT walking speed $(R=0.54, P<0.05)$, but not with single-task walking speed $(R=0.10)$.

\section{Discussion}

The aim of this study was to determine if the WTMT could detect people with early-stage EF impairment. Cluster analysis broke down the subjects into groups according to the similarities of the different walking variables. We noted that the groups were differentiated at both locomotor and cognitive levels.

In this study, we did not note any walking variables to analyze subjects' locomotor performances, but we did study the locomotor abilities of each subject during the WTMT. In the literature, one can observe that several walking variables, and not one alone, can reveal an alteration in dual-task locomotor performance. ${ }^{23,39}$ Moreover, some authors have associated an alteration in cognitive functions with a reduction in walking speed. ${ }^{21,22,40,41}$ Therefore, we think that integrating several walking variables in the statistical analysis reinforces the results.

The WTMT is characterized as a complex walking task, requiring the subject to plan his/her walking in a defined space, according to a goal. The aim is to use walking tests that are more related to spatial navigation than to stereotyped walking in a straight line, in which the subject is able to pace his/her walking frequency depending on the cognitive task. ${ }^{42}$

\section{Detection of cognitive impairment in the elderly by analysis of locomotor performances during WTMT}

Detailed study of the spatiotemporal variables of walking during the WTMT revealed three distinct groups. Group 1 subjects had the lowest performances in the WTMT and walked with cautious gaits during the test (ie, they greatly reduced their walking speeds, significantly increasing their times in double support). Group 3 subjects had intermediate locomotor performances that were between those of Groups 1 and 2, but were significantly different from each. Error analysis showed that, on average, one out of two older subjects committed at least one error during the WTMT (Table 1). Therefore, Group 1 subjects had the lowest performances in both domains (physical and cognitive).

In the literature, several authors have studied the performance of the elderly on the WTMT.,30,31 Alexander et al observed that the locomotor performances of WTMT subjects depended on their age. We agree with their first results because, in this study, the subjects who had the best WTMT performances were in Group 2, which was essentially made up of young adults (14 out of 15 subjects), whereas Groups 1 and 3 were composed of older subjects ( $>65$ years old). These results are different from those of another test that we recently developed (the Walking Stroop Carpet); in this study, healthy older subjects were grouped with young subjects. ${ }^{33}$

The WTMT has been identified in the literature as a test that is sensitive to the alteration of cognitive functions. ${ }^{31} \mathrm{In}$ order to study the relationship between gait and cognition in this population, we analyzed the cognitive profiles of the subjects in Groups 1 and 3. Analysis of the different MCI subgroups, according to Petersen's classification (2004), revealed that all of the MCI subjects with a dysexecutivetype syndrome (naMCI or mdMCI) were in Group 1 (nine out of nine subjects), whereas the aMCI subjects were mainly in Group 3 (four aMCI subjects out of six). In our study 
population, the WTMT was able to detect the dysexecutive syndrome with $100 \%$ sensitivity and $80 \%$ specificity. Persad et al (2008) reported similar results, since the group with EF alteration (naMCI and Alzheimer patients) had WTMT-B performances that were significantly more altered than the group of subjects without EF alteration (aMCI and healthy subjects). ${ }^{31}$

This strong relationship between EF impairment and reduction in walking abilities can be found in the literature, in particular, in studies of TMT performance. First of all, many authors have reported that low TMT performances are associated with a reduction in the overall physical abilities of older subjects, ${ }^{25}$ of subjects with MCI, ${ }^{43}$ and even as a predictor of early morbidity. ${ }^{24}$ Moreover, analysis of walking abilities has revealed that older subjects whose TMT performances were the poorest also presented a reduction in complex walking exercises, such as the Figure-of-Eight Walk test, ${ }^{28}$ a seven-meter walk, with obstacles. ${ }^{26,27}$ In the present study, we found the same relationship, since the $\triangle \mathrm{TMT}$ score was significantly correlated with walking speed during the WTMT, but not with single-task walking speed.

This relationship between cognitive and locomotor abilities does not appear to be linked with amnestic abilities. ${ }^{21,31,44}$ In this study, the aMCI and healthy older subjects were classified into the same groups according to their locomotor performances. One can suppose, therefore, that amnestic abilities do not have an impact on WTMT performance.

\section{Early detection of cognitive impairment that was not revealed in traditional neuropsychological tests}

Thorough clinical analysis of the older population revealed the presence of blMCI: subjects who presented neuropsychological test performances that were consistently on the verge of the pathological threshold. ${ }^{33}$ We noted that some blMCI subjects were classified by their WTMT locomotor performances (five out of nine subjects) in the same group (Group 1) as the MCI subjects with EF impairment (Figure 3). We can suppose that a complex walking exercise, such as the WTMT, makes it possible to detect subjects who were not diagnosed as MCI by traditional neuropsychological tests, but who, nevertheless, presented common impairments (alterations of locomotor abilities during complex walking, and reduction in EF performances). The WTMT has the ability to detect early EF (ie, the blMCI stage) with $78 \%$ sensitivity and $90 \%$ specificity. These values are slightly inferior to those obtained with the Walking Stroop Carpet. ${ }^{33}$
We suppose that blMCI subjects who present a major modification in walking variables during WTMT are more at risk to evolve towards an MCI state, even to dementia. Indeed, several authors have reported that subjects with MCI who have an abnormal gait during dual-task or complex walking situations are more at risk of developing dementia. ${ }^{18-20,45}$ These hypotheses suggest, once again, that walking impairment could play an important role in the diagnosis of dementia and that, even before the MCI stage, we can detect, through complex walking tests, older subjects who are likely to deteriorate at a cognitive level.

These differences in detection abilities, between our tests and those currently used, can be explained by the numerous limitations presented by traditional neuropsychological tests. Indeed, the performances of neuropsychological tests to evaluate EF vary according to numerous parameters, such as a lack of novelty, diagnostic variations dependent on threshold values, ${ }^{46}$ and the taking of medications. ${ }^{13}$ Moreover, the older subjects who participated in our study had high levels of education and were from high socioprofessional categories. Therefore, it is probable that these subjects had sufficient cognitive reserve to respond to traditional neuropsychological tests. On the other hand, we can suppose that this cognitive reserve would be negatively affected in a complex walking situation or when great attention is required. $^{47}$

\section{Limitations}

Our study showed that this test provides early detection of cognitive impairment, but did not give us values for clinical diagnostic use. It would be of interest to define a threshold value that would enable a clinician to decide on the presence of cognitive impairment and to make a diagnosis. Such a decision value, with confidence intervals, defined according to walking speed, could be studied in a broader population, in order to improve clinical diagnosis.

Our population is small, with regard to statistical treatment, because this study was based on only 36 older subjects and 15 young subjects. In addition, 27 out of the 32 subjects in Groups 1 and 2 were women.

Moreover, these tests should be performed on a larger population that includes Alzheimer patients, in order to determine whether they present the same motor performances as dysexecutive-type MCI subjects, or if they make up a new group in the cluster analysis. The monitoring of this population within the framework of a longitudinal study would make it possible to increase statistical power and to confirm previously developed clinical hypotheses. 


\section{Conclusion}

New walking tests, such as the WTMT, come close to everyday acts, in which walking situations are navigational situations, punctuated with sensory conflicts and interferences provoked by mental operations. The WTMT also detects older people with cognitive fragility (blMCI), who are likely to deteriorate. The WTMT is a test that is noninvasive and easily and quickly performed. This test requires low-cost equipment, which makes it possible to test a large proportion of a population.

\section{Disclosure}

The authors have no conflicts of interest to declare.

\section{References}

1. Petersen RC. Mild cognitive impairment as a diagnostic entity. J Intern Med. 2004;256(3):183-194.

2. Traykov L, Raoux N, Latour F, et al. Executive functions deficit in mild cognitive impairment. Cogn Behav Neurol. 2007;20(4):219-224.

3. Reinvang I, Grambaite R, Espeseth T. Executive dysfunction in MCI: subtype or early symptom. Int J Alzheimers Dis. 2012. 2012: 936272.

4. Chapman RM, Mapstone M, McCrary JW, et al. Predicting conversion from mild cognitive impairment to Alzheimer's disease using neuropsychological tests and multivariate methods. J Clin Exp Neuropsychol. 2011;33(2):187-199.

5. Clark LR, Schiehser DM, Weissberger GH, Salmon DP, Delis DC, Bondi MW. Specific measures of executive function predict cognitive decline in older adults. J Int Neuropsychol Soc. 2012;18(1):118-127.

6. Godefroy O. Frontal syndrome and disorders of executive functions. J Neurol. Jan 2003;250(1):1-6.

7. Miyake A, Friedman NP, Emerson MJ, Witzki AH, Howerter A, Wager TD. The unity and diversity of executive functions and their contributions to complex "Frontal Lobe" tasks: a latent variable analysis. Cogn Psychol. 2000;41(1):49-100.

8. Reitan RM, Tarshes EL. Differential effects of lateralized brain lesions on the trail making test. J Nerv Ment Dis. 1959;129:257-262.

9. Sanchez-Cubillo I, Perianez JA, Adrover-Roig D, et al. Construct validity of the Trail Making Test: role of task-switching, working memory, inhibition/interference control, and visuomotor abilities. J Int Neuropsychol Soc. 2009;15(3):438-450.

10. Tabert MH, Manly JJ, Liu X, et al. Neuropsychological prediction of conversion to Alzheimer disease in patients with mild cognitive impairment. Arch Gen Psychiatry. 2006;63(8):916-924.

11. Lopez OL, Becker JT, Jagust WJ, et al. Neuropsychological characteristics of mild cognitive impairment subgroups. J Neurol Neurosurg Psychiatry. 2006;77(2):159-165.

12. Brooks BL, Strauss E, Sherman EMS, Iverson GL, Slick DJ. Developments in neuropsychological assessment: Refining psychometric and clinical interpretive methods. Canadian Psychology. 2009;50(3): 196-209.

13. Weston AL, Weinstein AM, Barton C, Yaffe K. Potentially inappropriate medication use in older adults with mild cognitive impairment. J Gerontol A Biol Sci Med Sci. 2010;65(3):318-321.

14. Abellan van Kan G, Rolland Y, Andrieu S, et al. Gait speed at usual pace as a predictor of adverse outcomes in community-dwelling older people an International Academy on Nutrition and Aging (IANA) Task Force. J Nutr Health Aging. 2009;13(10):881-889.

15. Waite LM, Grayson DA, Piguet O, Creasey H, Bennett HP, Broe GA. Gait slowing as a predictor of incident dementia: 6-year longitudinal data from the Sydney Older Persons Study. J Neurol Sci. 2005;229-230: 89-93.
16. Verghese J, Lipton RB, Hall CB, Kuslansky G, Katz MJ, Buschke H. Abnormality of gait as a predictor of non-Alzheimer's dementia. N Engl J Med. 2002;347(22):1761-1768.

17. Verghese J, Derby C, Katz MJ, Lipton RB. High risk neurological gait syndrome and vascular dementia. J Neural Transm. 2007;114(10): 1249-1252.

18. Hausdorff JM, Buchman AS. What links gait speed and MCI with dementia? A fresh look at the association between motor and cognitive function. J Gerontol A Biol Sci Med Sci. 2013;68(4):409-411.

19. Verghese J, Wang C, Lipton RB, Holtzer R. Motoric cognitive risk syndrome and the risk of dementia. J Gerontol A Biol Sci Med Sci. 2013;68(4):412-418.

20. Montero-Odasso M, Bergman H, Phillips NA, Wong CH, Sourial N, Chertkow H. Dual-tasking and gait in people with mild cognitive impairment. The effect of working memory. BMC Geriatr. 2009;9:41.

21. van Iersel MB, Kessels RP, Bloem BR, Verbeek AL, Olde Rikkert MG. Executive functions are associated with gait and balance in communityliving elderly people. J Gerontol A Biol Sci Med Sci. 2008;63(12): 1344-1349.

22. Beauchet O, Annweiler C, Montero-Odasso M, Fantino B, Herrmann FR, Allali G. Gait control: a specific subdomain of executive function? J Neuroeng Rehabil. 2012;9:12.

23. Yogev-Seligmann G, Hausdorff JM, Giladi N. The role of executive function and attention in gait. Mov Disord. 2008;23(3):329-342; quiz 472.

24. Hirota C, Watanabe M, Sun W, et al. Association between the Trail Making Test and physical performance in elderly Japanese. Geriatr Gerontol Int. 2010;10(1):40-47.

25. Vazzana R, Bandinelli S, Lauretani F, et al. Trail Making Test predicts physical impairment and mortality in older persons. J Am Geriatr Soc. 2010;58(4):719-723.

26. Ble A, Volpato S, Zuliani G, et al. Executive function correlates with walking speed in older persons: the InCHIANTI study. $J$ Am Geriatr Soc. 2005;53(3):410-415.

27. Coppin AK, Shumway-Cook A, Saczynski JS, et al. Association of executive function and performance of dual-task physical tests among older adults: analyses from the InChianti study. Age Ageing. Nov 2006;35(6):619-624.

28. Hess RJ, Brach JS, Piva SR, VanSwearingen JM. Walking skill can be assessed in older adults: validity of the Figure-of- 8 Walk Test. Phys Ther. 2010;90(1):89-99.

29. Hobert MA, Niebler R, Meyer SI, et al. Poor trail making test performance is directly associated with altered dual task prioritization in the elderly - baseline results from the TREND study. PLoS One. 2011; 6(11):e27831.

30. Alexander NB, Ashton-Miller JA, Giordani B, Guire K, Schultz AB. Age differences in timed accurate stepping with increasing cognitive and visual demand: a walking trail making test. J Gerontol A Biol Sci Med Sci. 2005;60(12):1558-1562.

31. Persad CC, Jones JL, Ashton-Miller JA, Alexander NB, Giordani B. Executive function and gait in older adults with cognitive impairment. J Gerontol A Biol Sci Med Sci. Dec 2008;63(12):1350-1355.

32. Yamada M, Ichihashi N. Predicting the probability of falls in community-dwelling elderly individuals using the trail-walking test. Environ Health Prev Med. 2010;15(6):386-391.

33. Perrochon A, Kemoun G, Watelain E, Berthoz A. Walking Stroop carpet: an innovative dual-task concept for detecting cognitive impairment. Clin Interv Aging. 2013;8:317-328.

34. Folstein MF, Folstein SE, McHugh PR. "Mini-mental state". A practical method for grading the cognitive state of patients for the clinician. J Psychiatr Res. Nov 1975;12(3):189-198.

35. Dubois B, Slachevsky A, Litvan I, Pillon B. The FAB: a Frontal Assessment Battery at bedside. Neurology. 2000;55(11):1621-1626.

36. Lord SR, Clark RD, Webster IW. Visual acuity and contrast sensitivity in relation to falls in an elderly population. Age Ageing. 1991;20(3): $175-181$. 
37. Ward JH. Hierarchical grouping to optimize an objective function. J Am Stat Assoc. 1963;58:236-244.

38. Hartigan JA. Clustering Algorithms (Probability and Mathematical Statistics). Hoboken, NJ: John Wiley and Sons; 1975.

39. Al-Yahya E, Dawes H, Smith L, Dennis A, Howells K, Cockburn J. Cognitive motor interference while walking: a systematic review and meta-analysis. Neurosci Biobehav Rev. 2011;35(3):715-728.

40. Sheridan PL, Solomont J, Kowall N, Hausdorff JM. Influence of executive function on locomotor function: divided attention increases gait variability in Alzheimer's disease. J Am Geriatr Soc. 2003;51(11): 1633-1637.

41. Allali G, Assal F, Kressig RW, Dubost V, Herrmann FR, Beauchet O. Impact of impaired executive function on gait stability. Dement Geriatr Cogn Disord. 2008;26(4):364-369.

42. Beauchet O, Allali G, Poujol L, Barthelemy JC, Roche F, Annweiler C. Decrease in gait variability while counting backward: a marker of "magnet effect"? J Neural Transm. 2010;117(10):1171-1176.
43. McGough EL, Kelly VE, Logsdon RG, et al. Associations between physical performance and executive function in older adults with mild cognitive impairment: gait speed and the timed "up and go" test. Phys Ther. 2011;91(8):1198-1207.

44. Hausdorff JM, Yogev G, Springer S, Simon ES, Giladi N. Walking is more like catching than tapping: gait in the elderly as a complex cognitive task. Exp Brain Res. 2005;164(4):541-548.

45. Montero-Odasso M, Verghese J, Beauchet O, Hausdorff JM. Gait and cognition: a complementary approach to understanding brain function and the risk of falling. J Am Geriatr Soc. 2012;60(11):2127-2136.

46. Kochan NA, Slavin MJ, Brodaty H, et al. Effect of different impairment criteria on prevalence of "objective" mild cognitive impairment in a community sample. Am J Geriatr Psychiatry. 2010;18(8):711-722.

47. Holtzer R, Wang C, Lipton R, Verghese J. The protective effects of executive functions and episodic memory on gait speed decline in aging defined in the context of cognitive reserve. J Am Geriatr Soc. 2012; 60(11):2093-2098.
Clinical Interventions in Aging

\section{Publish your work in this journal}

Clinical Interventions in Aging is an international, peer-reviewed journal focusing on evidence-based reports on the value or lack thereof of treatments intended to prevent or delay the onset of maladaptive correlates of aging in human beings. This journal is indexed on PubMed Central, MedLine, the American Chemical Society's 'Chemical Abstracts

\section{Dovepress}

Service' (CAS), Scopus and the Elsevier Bibliographic databases. The manuscript management system is completely online and includes a very quick and fair peer-review system, which is all easy to use. Visit http://www.dovepress.com/testimonials.php to read real quotes from published authors. 